\title{
SEPARATION OF OIL PALM KERNEL AND SHELL MIXTURE USING SOIL AND PALM ASH SLURRIES
}

\author{
R. S. Agu ${ }^{1}$, P. C. Eze ${ }^{2, *}$ and C. U. Omeje ${ }^{3}$ \\ ${ }^{1}$ DePartment of Agricultural TeChnology, EnUgu State PolyteChnic, IWollo, EnUgu State. Nigeria. \\ 2 Dept. of Agric. \& Bioresource Engr., EnUgu State University of SCIENCE AND TECH., ENUGU STATE, NigERIA. \\ 3 Department of General Studies, Enugu State Polytechnic, Iwollo, Enugu State. NiGERIA \\ E-mail address: ${ }^{1}$ aguromanus@gmail.com, 2 paul.eze@esut.edu.ng, 3 omejecu@gmail.com
}

\begin{abstract}
This study investigated the possibility of separating oil palm kernel and shell mixture using media other than clay in wet separation. The separation efficiency of each medium ["Ikwube" (anthill), palm ash and sandy loam soil] was compared with that of clay. The effect of media type, specific gravity of the slurry, $\mathrm{pH}$ and slurry viscosity on the efficiency of separation were studied. The media/water ratio of 0.20:1, 0.30:1, 0.40:1, and 0.50:1 by weight were prepared in four aluminum pots for each medium at a time and each used to separate $20 \mathrm{~kg}$ of cracked nut (palm kernel and shell mixture). The specific gravity and viscosity increases with increase in media/water ratio while the pH decreases. Higher slurry viscosity resulted in a better separation but there is decrease in the efficiency when viscosity is above 3.5 and $5.5 \mathrm{cP}$ for clay and "Ikwube" respectively. The suitable media slurries were found to have specific gravities between 1.04 and 1.12. The optimum condition in which separation efficiency was found in the media/water ratio of 0.30:1. Among the media used, "Ikwube" was found to be comparable to clay at a medium-to-water ratio of 0.30:1 giving 98.93\% efficiency. Thus, it is recommended that "Ikwube" can be used in place of clay for wet separation.
\end{abstract}

\section{Key words: Oil Palm Kernel, Kernel Shell, Separation, Clay Soil, "Ikwube" (anthill).}

\section{INTRODUCTION}

Oil palm is a unique crop where two distinct types of oil are obtained. The palm oil is obtained from the mesocarp of the fruit after a digestion process and the palm kernel oil is obtained from its kernel. Both of which are mainly triglycerides and chemically and physically different from each other with palm oil having high palmitic acid ( $\mathrm{C}_{16}$ fatty acid) and palm kernel oil having high lauric and myristic acids ( $\mathrm{C}_{12}$ and $\mathrm{C}_{14}$ fatty acids respectively) [1]. Palm kernel oil is very valuable because it contains lauric acid, which is a useful fatty acid used to produce soaps, washing powders and personal care products. There are only two lauric oils, coconut oil (CNO) and palm kernel oil (PKO).They are called lauric because lauric acid is the major fatty acid in their composition at about 50\%, while no other major oil contains more than $1 \%$ (butter fat contains 3\%) [2]. To obtain the PKO, the nut of the oil palm must pass through a digestion processes from where the palm oil is produced. The dried palm kernel nut is cracked either at a ripple mill or the use of Rolek nut cracker thereby producing a mixture of the shell and kernel. Kernel is an edible endosperm, which is covered by reddish brown to black testa which fits tightly into the shell and varies in shapes and sizes depending on the shape and size of the nuts and a good industrial raw material [3]. Removal of palm kernel from its shell basically, involves cracking and separation processes. The separation of palm kernels from the shells is an important process in the recovery of the kernels for extraction of PKO. The technique for this separation is of two types: the wet and the dry methods. The dry separation involves the use of winnowing column while the wet separation involves water and clay or other media [4]. Palm kernel processing industry is very popular in the third world countries because of the dependency of many companies on palm kernel and palm oil as raw material [5, 6]. In the developing countries, small - scale palm mills make use of manual labour for the separation of the kernels and shells, where the kernels are handpicked from the mixture and at the same time, the unbroken nuts are recovered and taken back to the mill for cracking. This method is slow, laborious and unsuitable for large - scale mills, but there are now modern methods of separation, which are classified into two, namely: the wet and the dry methods. The wet method employs the difference in density between the kernel and the shell to achieve separation while the dry method uses their difference in shape to

* Corresponding author, tel: +234-803-264-2302 
achieve same. The relative density of palm kernel is about 1.07 and that of the shell ranges from 1.15 to 1.20 . Clay-bath and hydro-cyclones are two methods devised for cracked mixture separations based on density. These methods of separation are usually known as wet processes since water is always involved and the kernels have to be dried at the end of the separation [7]. Over the years, there have been a lot of innovations geared towards improving the efficiency of these activities by way of reducing energy consumption, water usage, and minimizing damage or rupture of the kernels, noise generation, and generation of palm oil mill effluent. Separation of cracked mixture is a challenging process especially to the small-scale mill owners. Large-scale mills have automated hydro-cyclone machines with high separation efficiency, however, clay-baths and hydro cyclones are known for their high energy and water consumption making their application in small-scale mills difficult [8]. On the other hand, inefficient separation process could cause shells to be carried together with kernel to palm kernel expellers which could damage the crushing mechanisms.

This study focused on the use of soil types other than clay and palm bunch ashes in wet separation and aimed at separating the mixtures of Palm Kernel and Shell using "Ikwube" (anthill), palm ash and sandy loam soil and comparing their separation efficiency with that of clay soil in wet separation.

Table 1: Physical Properties of oil palm kernels and shells

\begin{tabular}{llll}
\hline Materials & Diameter $(\mathrm{cm})$ & $\begin{array}{l}\text { Specific } \\
\text { Gravity }\end{array}$ & $\begin{array}{l}\text { Average } \\
\text { Specific } \\
\text { Gravity }\end{array}$ \\
\hline \multirow{3}{*}{ Kernel } & $<1.0$ & 0.95 & \\
& $1.0-1.5$ & 1.05 & 1.04 \\
\multirow{2}{*}{ Shell } & $1.5-2.0$ & 1.12 & \\
& $<1.0$ & 1.24 & \\
& $1.0-1.5$ & 1.28 & 1.28 \\
\hline
\end{tabular}

\section{MATERIALS AND METHODS}

\subsection{Sample Collection}

The palm kernels and palm bunch ash used for this work were collected from a palm oil mill at Umuitodo Obollo Nkwo in Udenu L.G.A of Enugu State, Nigeria, which is located at Latitude $6.8^{\circ} \mathrm{N}$, longitude $7.29^{\circ} \mathrm{E}$. The soil sample [Figure 1(i)] and Ikwube [Figure 1(ii)] used in this work were collected within the same community. Ikwube is a processed soil of anthill structure formed by ants, termites, etc as shown in Figure 1(ii).

The empty bunches were sundried for one week. Open burning method was employed, i.e. collecting the palm bunch wastes in heaps and burning and afterwards, the ashes were allowed to cool before pulverizing by grinding using mortar and pestle, and sieving using a $150 \mu \mathrm{m}$ BS sieve.

\subsection{Preparation of Samples}

The oil palm kernels are smooth and nearly spherical while the oil palm shells are semi-circular in shape but with greater tendency to being flat. After the palm nut was cracked, the kernels were released due to the fragmentation of the shells.

A pre-analysis of some sample of kernels [Figure 2 (i)] and shells [Figure 2 (ii)] were done to determine the physical properties; characteristic dimensions and specific gravities as shown in Table 1. The result showed that the specific gravity of oil palm kernels and shells differ significantly, hence the mixture of oil palm kernels and shells can be separated by using the heavy media separation process [9].

Both the soil and Ikwubes oil samples [Fig. 1 (i) and (ii)] were taken to Soil Science Research Laboratory, Department of Soil Science, University of Nigeria, Nsukka for particle size analysis and textural class determination. The result of the soil analysis is as presented in Table 2. From the laboratory analysis, the Ikwube was found to be sandy clay loam while the soil collected from the said site was sandy loam.

\subsection{Experimental Procedure}

The kernel/shell separation was performed using the slurry prepared with each of the soil sample and water. The process used water mixed with the different samples collected for the study with a density intermediate between the solids to be separated. The Ikwube were pounded into fine particles and kept to dry in the sun. The other soil samples were also dried to a moisture content of $5 \%$ w.b. Four aluminium cooking pots of 50 litres capacity were set and labelled 1 to 4 .

Table .2: Particle Size Distribution of Soils Sample Showing Soil Textural Class

\begin{tabular}{|c|c|c|c|c|c|c|c|c|c|c|c|}
\hline \multirow{2}{*}{$\begin{array}{l}\text { Sample } \\
\text { Description }\end{array}$} & \multicolumn{2}{|c|}{$\mathrm{pH}$ value } & \multirow{2}{*}{$\begin{array}{l}\text { Clay } \\
(\%)\end{array}$} & \multirow[t]{2}{*}{ Content } & \multirow{2}{*}{$\begin{array}{l}\text { Silt } \\
(\%)\end{array}$} & \multirow[t]{2}{*}{ Content } & \multirow{2}{*}{$\begin{array}{l}\text { F.S } \\
(\%)\end{array}$} & \multirow[t]{2}{*}{ Content } & \multirow{2}{*}{$\begin{array}{l}\text { C.S } \\
(\%)\end{array}$} & \multirow[t]{2}{*}{ Content } & \multirow{2}{*}{$\begin{array}{l}\text { Textural } \\
\text { Class }\end{array}$} \\
\hline & $\mathrm{H}_{2} \mathrm{O}$ & KCL & & & & & & & & & \\
\hline Ikwube & 5.9 & 4.6 & 29 & & 15 & & 42 & & 14 & & SCL \\
\hline Soil sample & 5.8 & 4.5 & 13 & & 19 & & 67 & & 1 & & SL \\
\hline
\end{tabular}

$\mathrm{SCL}=$ Sandy Clay Loam (Ikwube), $\mathrm{SL}=$ Sandy Loam, $\mathrm{H}_{2} \mathrm{O}=$ Water, $\mathrm{KCl}=$ Potassium chloride, $\mathrm{F} . \mathrm{S}=$ Fine sand, C.S = Coarse sand. 


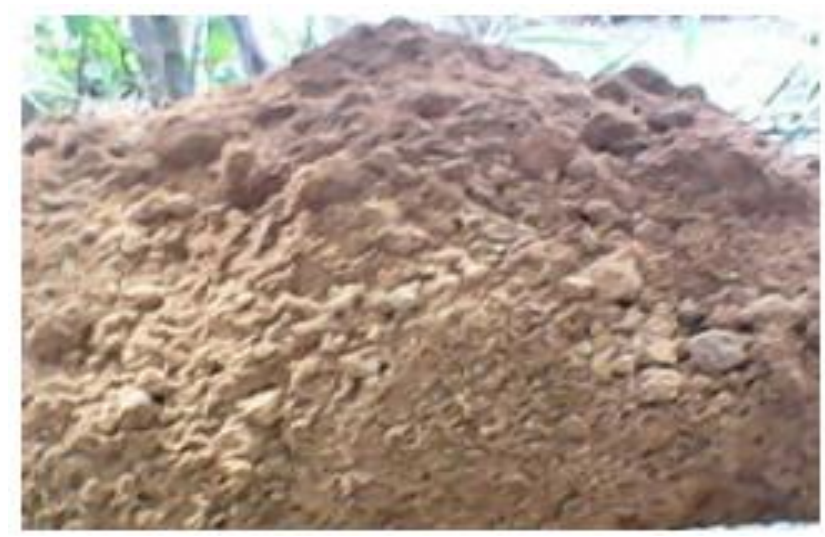

Fig. 1(i): Sandy Loam Soil

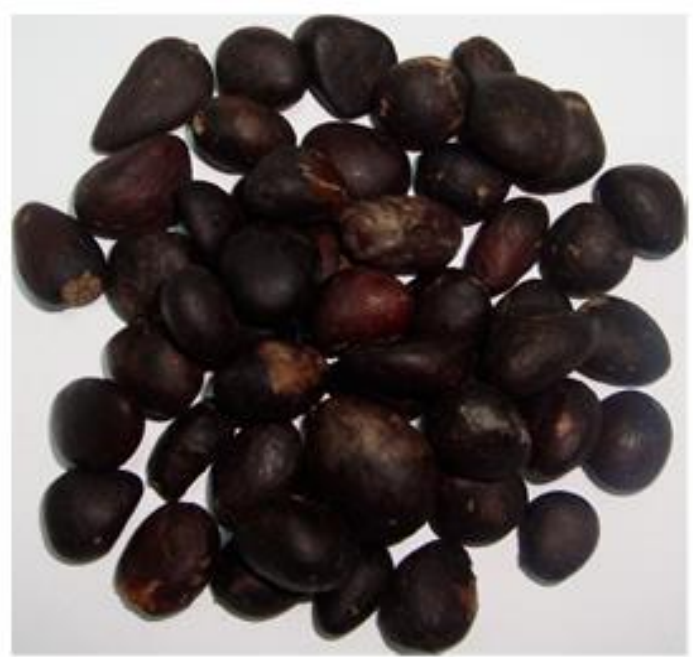

Figure 2: (i) Palm Kernels

The soil samples were collected and mixed with water in pot $1,2,3$ and 4 in the ratios $0.20: 1,0.30: 1,0.40: 1$ and $0.50: 1$ by weight respectively.

The $\mathrm{pH}$, specific gravity and the slurry viscosity were measured using Sartorius-model pH meter, Hydrometer and Brookfield Rotational Viscometer respectively and the values shown in Table 3.

A mixture of kernel/shell weighing $20 \mathrm{~kg}$ were poured into pot 1 and manually stirred vigorously. The floating kernels were scooped with the sieve. The scooped kernels were washed, dried and weighed. The sunk shells were collected, washed, dried and weighed. The dry scooped kernels were sorted for impurities (unbroken kernels and shell fragments) and the kernels and impurities weighed. The collected shells were sorted for impurities (kernels and uncracked nuts and both weighed. Similar process was undertaken for the other pots and same procedure was then repeated for the other three samples.

The mixture was separated into its component parts by the tendency of the heavier material to sink and the lighter material to float. In other words, two products

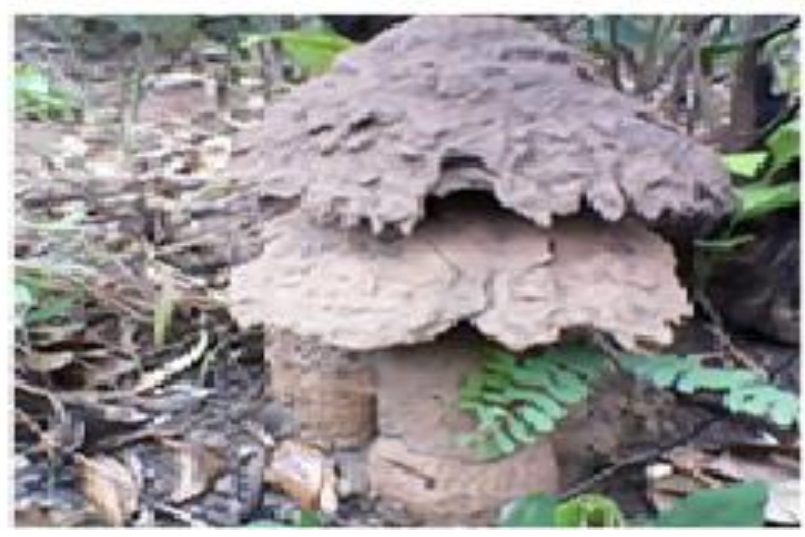

(ii) Anthill Soil (Ikwube)

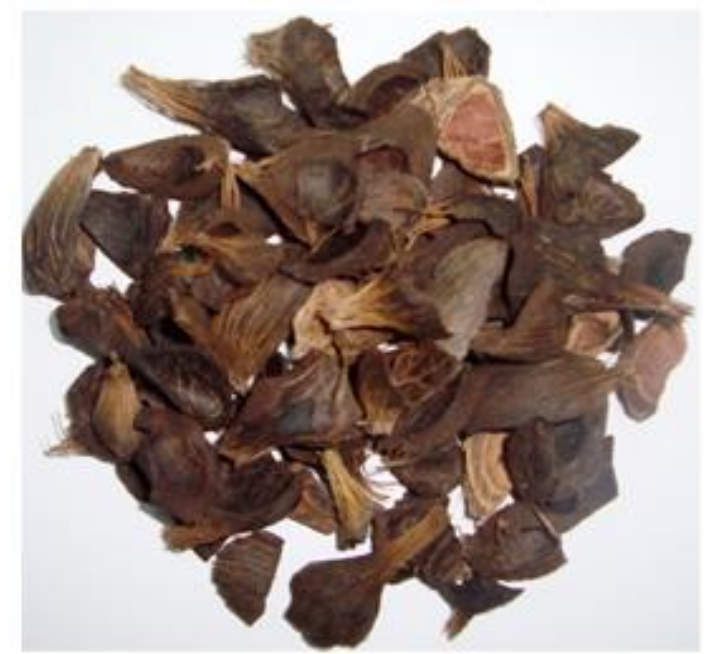

(ii) Kernel Shells

were produced: an under flow enriched with heavier particles and an over flow rich in low density particles. The over flow and under flow samples for all tests were collected and analyzed in terms of efficiency of kernel recovery and shell recovery, respectively. The kernels recovery were determined from the measurements of the amount of kernels found in the kernels collection tank and the total amount of kernels contained in the feed mixture of oil palm kernels and shells. Finally, shell recovery was determined from the measurements of the amount of shells found in the shells collection tank and the total amount of shells contained in the feed mixture of oil palm kernels and shells. The separation and recovery efficiency for each medium used were evaluated as indicated below:

\subsubsection{Kernel Recovery $\left(K_{r}\right)$ :}

This is the percentage of the kernels in the feed mixture recovered in the kernel collection tank, it was calculated using the equation 1 .

$$
K_{r}=\frac{a}{a+b} \times 100
$$


In (1), a is the weight in grams of recovered kernels found in the kernel collection tank and $\mathrm{b}$ is the weight in grams of kernels that sunk with the separated shells found in the shells collection tank.

\subsubsection{Kernel Contaminant $\left(K_{c}\right)$ :}

This refers to the percentage of shell, uncracked nuts and other impurities found in the kernels collection tank. The smaller the amount, the higher the purity of kernels separated. $\mathrm{K}_{\mathrm{c}}$ in $\%$ was calculated from the expression in equation 2.

$$
K_{c}=\frac{C}{a+C} \times 100
$$

Where, $\mathrm{c}=$ the weight in grams of shells, uncracked nuts and other impurities found in the kernels collection container at the end of the run, and "a" as defined above.

\subsubsection{Shell Recovery $\left(S_{r}\right)$ :}

This is the percentage of shells in the feed mixture recovered in the shells collecting tank, and was calculated by using the expression in equation 3 .

$$
S_{r}=\frac{d}{d+e} \times 100
$$

Where, $d=$ the weight in grams of shells found in the shell collection tank; $\mathrm{e}=$ the weight in grams of the shells found in the kernels collection tank.

\subsubsection{Shell contaminant}

$\left(\mathrm{S}_{\mathrm{c}}\right)$ in \% was calculated from the expression in equation 4.

$$
S_{c}=\frac{f}{d+f} \times 100
$$

Where, $f=$ the weight of kernels, uncracked nuts and other impurities contained in the shells collection tank.

\section{RESULT AND DISCUSSION}

This work investigated the efficiency of oil palm kernels and shells separation processes using Ikwube, Palm Ash and Sandy Loam, and comparing the separation efficiency with that of clay. The effect of slurry (m:w) ratio, sample type and media/sample properties such as specific gravity, $\mathrm{pH}$ and viscosity of the slurry on the efficiency of separation were studied (Table 3). However, from the values obtained for the specific gravity and viscosity of the sample slurries, it is seen that the viscosity of all media slurry increases as the specific gravity increases. Authors from the review $[5,10]$ opined that the optimum for the specific gravity of the media slurry is between those specific gravities of the oil palm kernels and shells and the suitable media slurries were found to have specific gravities between 1.06 and 1.17. This is in line with the results of this study because most media slurries in this work fall between 1.04 and 1.20.
In the oil palm kernels and shells separation process, it has been reported that the alkalinity of the media slurry is suitable for these separations to remove the oil palm kernels from the shells but should not be intensely alkaline ( $\mathrm{pH}$ should be at range of 10) to prevent corrosion problems with process equipment [11]. From the result, it was found that the efficiency of separation depends on specific gravity and viscosity of the slurry, type and particle size of media. As the specific gravity and viscosity increases, the separation efficiency increases. Although, the separation efficiency starts decreasing at the ratio of $0.50: 1$ in all the media slurry studied. However, the results show that separation efficiency increases with decrease in $\mathrm{pH}$ value for each media slurry ratio.

Tables 3 and 4 show that as the media slurry increases in its ratio, the specific gravity and viscosity increases while the $\mathrm{pH}$ decreases. In general terms, Table 4 indicates that the optimum condition in which separation efficiency was found is the media slurry ratio of $0.30: 1$. Also, it was found that separation efficiency increases with decrease in viscosity for most media slurry ratio. The lower values in kernel recovery for every types of media slurry such as in ratios of 0.4:1, and 0.5:1 with corresponding higher $\mathrm{pH}$ value may be attributed to the viscosity of these operations which result to the slowness of the kernels to present themselves for separation.

From Table 3, this work shows that for the wet separation carried out with Clay, Ikwube, Palm Ash and Sandy Loam at 0.20:1 slurry ratio, clay has the highest separation efficiency of $95.76 \%$. Ikwube, Sandy Loam and Palm Ash with separation efficiency of $86.64 \%$, $43.23 \%$ and $7.01 \%$ respectively. In the same vain at $0.20: 1$, Table 4 reveals that the total kernel contaminants for Ikwube, Palm Ash and Sandy Loam is 1.09\%, 2.13\%, $8.22 \%$ and $6.10 \%$ respectively. This shows that Palm Ash has the highest contaminant while clay has the lowest contaminant at $0.20: 1$ slurry ratio.

Table 4 revealed that the total shell recovered as a result of using Clay, Ikwube, Palm Ash and Sandy Loam as media slurry for the wet separation were $99.91 \%$, $99.89 \%, 51.78 \%$ and $79.00 \%$ respectively at $0.20: 1$ slurry ratio. In each of the media slurry used, the percentage shell contaminants were 4.17\%, 11.84, 18.44 and $26.66 \%$ for Clay, Ikwube, Palm Ash and Sandy Loam media slurry respectively.

Table 4 also shows that for the wet separation carried out with Clay, Ikwube, Palm Ash and Sandy Loam at $0.30: 1$ slurry ratio, clay has the largest kernel recovery of $100.00 \%$, followed by ikwube which produced $98.93 \%$ recovery, and then by Sandy Loam recovering $60.65 \%$ and lastly Palm Ash which recovered the lowest quantity of kernel at $58.06 \%$. 
Table 3: Results of Separation with different media slurry at different Slurry Ratios

\begin{tabular}{|c|c|c|c|c|c|c|c|c|}
\hline \multirow{2}{*}{ Slurries } & \multirow{2}{*}{ Slurry ratio M:W } & \multirow{2}{*}{ SG } & \multirow{2}{*}{ pH Value } & \multirow{2}{*}{ Viscosity (cP) } & \multicolumn{2}{|c|}{ Kernel } & \multicolumn{2}{|c|}{ Shell } \\
\hline & & & & & Float (\%) & Sink (\%) & Float (\%) & Sink (\%) \\
\hline \multirow{4}{*}{ Clay } & $0.20: 1$ & 1.12 & 9.24 & 3.50 & 95.76 & 4.24 & 0.09 & 99.91 \\
\hline & $0.30: 1$ & 1.16 & 9.22 & 3.50 & 100.00 & 0.00 & 0.47 & 99.53 \\
\hline & $0.40: 1$ & 1.22 & 9.19 & 3.50 & 100.00 & 0.00 & 1.56 & 98.44 \\
\hline & $0.50: 1$ & 1.27 & 9.08 & 4.00 & 100.00 & 0.00 & 5.15 & 94.85 \\
\hline \multirow{5}{*}{ Ikwube } & $0.20: 1$ & 1.09 & 10.12 & 4.00 & 86.64 & 13.36 & 0.11 & 99.89 \\
\hline & $0.30: 1$ & 1.12 & 10.09 & 5.50 & 100.00 & 0.00 & 0.15 & 99.85 \\
\hline & $0.40: 1$ & 1.16 & 10.07 & 7.00 & 97.93 & 2.07 & 0.11 & 99.89 \\
\hline & $0.50: 1$ & 1.18 & 10.03 & 13.00 & 100.00 & 0.00 & 0.42 & 99.58 \\
\hline & $0.20: 1$ & 1.07 & 12.60 & 6.50 & 27.01 & 72.99 & 24.00 & 76.00 \\
\hline \multirow{2}{*}{ Palm Ash } & $0.30: 1$ & 1.12 & 12.51 & 12.00 & 68.06 & 31.94 & 13.00 & 87.00 \\
\hline & $0.40: 1$ & 1.17 & 12.39 & 28.00 & 97.72 & 2.28 & 7.00 & 93.00 \\
\hline \multirow{5}{*}{ Sandy Loam } & $0.50: 1$ & 1.20 & 12.29 & 65.00 & 100.00 & 0.00 & 0.56 & 99.44 \\
\hline & $0.20: 1$ & 1.04 & 9.12 & 8.50 & 63.23 & 36.77 & 5.00 & 95.00 \\
\hline & $0.30: 1$ & 1.05 & 9.07 & 12.00 & 82.81 & 17.19 & 14.10 & 85.90 \\
\hline & $0.40: 1$ & 1.07 & 9.03 & 27.00 & 95.02 & 4.98 & 9.92 & 90.08 \\
\hline & $0.50: 1$ & 1.09 & 9.98 & 60.00 & 96.07 & 3.93 & 2.81 & 97.20 \\
\hline
\end{tabular}

$+\mathrm{M}: \mathrm{W}=$ Media: Water, $\mathrm{SG}=$ Specific Gravity, $\mathrm{cP}=$ centipoise

Table 4: Separation Efficiency of Sample Slurries at different Slurry Ratios

\begin{tabular}{|c|c|c|c|c|c|c|c|c|}
\hline \multirow{2}{*}{ Slurries } & \multirow{2}{*}{ Slurry ratio M:W } & \multirow{2}{*}{ SG } & \multirow{2}{*}{ pH Value } & \multirow{2}{*}{ Viscosity (cP) } & \multicolumn{2}{|c|}{ Kernel } & \multicolumn{2}{|c|}{ Shell } \\
\hline & & & & & $\% \mathrm{~K}_{\mathrm{r}}$ & $\% \mathrm{~K}_{\mathrm{c}}$ & $\% \mathrm{~S}_{\mathrm{r}}$ & $\% \mathrm{~S}_{\mathrm{c}}$ \\
\hline \multirow{4}{*}{ Clay } & $0.20: 1$ & 1.12 & 9.24 & 3.50 & 95.76 & 1.09 & 99.91 & 4.17 \\
\hline & $0.30: 1$ & 1.16 & 9.22 & 3.50 & 100.00 & 0.46 & 100.00 & 0.00 \\
\hline & $0.40: 1$ & 1.22 & 9.19 & 3.50 & 100.00 & 1.49 & 100.00 & 0.00 \\
\hline & $0.50: 1$ & 1.27 & 9.08 & 4.00 & 100.00 & 4.78 & 100.00 & 0.00 \\
\hline \multirow{4}{*}{ Ikwube } & $0.20: 1$ & 1.09 & 10.12 & 4.00 & 86.64 & 2.13 & 99.89 & 11.84 \\
\hline & $0.30: 1$ & 1.12 & 10.09 & 5.50 & 100.00 & 0.11 & 99.85 & 2.03 \\
\hline & $0.40: 1$ & 1.16 & 10.07 & 7.00 & 98.93 & 1.49 & 99.89 & 0.00 \\
\hline & $0.50: 1$ & 1.18 & 10.03 & 13.00 & 95.00 & 4.78 & 99.58 & 6.80 \\
\hline \multirow{4}{*}{ Palm Ash } & $0.20: 1$ & 1.07 & 12.60 & 6.50 & 70.01 & 8.22 & 51.78 & 18.44 \\
\hline & $0.30: 1$ & 1.12 & 12.51 & 12.00 & 58.06 & 0.70 & 75.78 & 4.22 \\
\hline & $0.40: 1$ & 1.17 & 12.39 & 28.00 & 52.72 & 1.56 & 97.77 & 0.43 \\
\hline & $0.50: 1$ & 1.20 & 12.29 & 65.00 & 51.00 & 4.60 & 92.90 & 17.10 \\
\hline \multirow{4}{*}{ Sandy Loam } & $0.20: 1$ & 1.04 & 9.12 & 8.50 & 73.23 & 6.10 & 79.00 & 26.66 \\
\hline & $0.30: 1$ & 1.05 & 9.07 & 12.00 & 60.65 & 0.81 & 87.90 & 2.30 \\
\hline & $0.40: 1$ & 1.07 & 9.03 & 27.00 & 58.00 & 1.92 & 91.89 & 1.23 \\
\hline & $0.50: 1$ & 1.09 & 9.98 & 60.00 & 54.00 & 2.68 & 87.98 & 25.32 \\
\hline
\end{tabular}

${ }^{+} \mathrm{M}: \mathrm{W}=$ Media:Water, $\mathrm{SG}=$ Specific Gravity, $\mathrm{K}_{\mathrm{r}}=$ Kernel Recovery, $\mathrm{K}_{\mathrm{c}}=$ Kernel Contaminant, $\mathrm{S}_{\mathrm{r}}=$ Shell Recovery, $\mathrm{S}_{\mathrm{c}}=$ Shell Contaminant, $\mathrm{cP}=$ centipoises

In regards to the kernel contaminants, Table 4 shows that Ikwube slurry does not have any contaminant at all when used for the separation whereas the contaminants found using clay, Palm Ash and sandy loam media slurry were $0.46 \%, 0.70 \%$ and $0.81 \%$ respectively.

As indicated in Table 4, the data revealed that the total shell recovered as a result of using Clay, Ikwube, Palm Ash and Sandy Loam as media slurry for the clay bath separation were $100.00 \%, 99.85 \%, 75.78 \%$ and $87.90 \%$ respectively $0.30: 1$ slurry ratio. On the other hand, Table 4 also showed that the percentage shell contaminants in each of the media slurry used at media slurry ratio of $0.30: 1$ were $0.00 \%, 2.03 \%, 4.22 \%$ and $2.30 \%$ for Clay, Ikwube, Palm Ash and Sandy Loam respectively.
Table 3 also shows that the percentage kernel recovery for Clay, Ikwube, Palm Ash and Sandy Loam media slurry were $100 \%, 100 \%, 65.72 \%$ and $68.00 \%$ respectively at $0.40: 1$ slurry ratio; which showed that the amount of kernel recovered using clay and Ikwube are the same and at the same time were very high while that of Palm Ash and sandy loam are also related. In the same vain at $0.30: 1$, the total kernel contaminants for Clay, Ikwube, Palm Ash and sandy loam is $1.49 \%, 0.11 \%, 1.56 \%$ and $1.92 \%$ respectively. Table 4 shows that sandy loam has the highest contaminant while Ikwube has the lowest contaminant at 0.30:1 slurry ratio.

As shown from Table 4, (columns 8 and 9) at 0.40:1 slurry ratio, the efficiency of shell recovery and shell 
contaminants, was $100 \%$ for clay while that of Ikwube, Palm Ash and Sandy Loam were 99.89\%, 97.77\% and $91.89 \%$ respectively.

With regards to the shell contaminants, clay and Ikwube slurry produced no contaminant whereas the contaminants found using Palm Ash and sandy loam media slurry were 0.43 and 1.23 respectively.

From Table 4, the study shows that for the separation carried out with Clay, Ikwube, Palm Ash and Sandy Loam at $0.50: 1$ slurry ratio, clay has the largest kernel recovery, of $100.00 \%$, followed by Ikwube which produced $95.00 \%$ recovery, and then by Sandy Loam recovering 64.00\% and lastly Palm Ash which recovered the lowest quantity of kernel at $61.00 \%$.

Accordingly, table 4 shows that at 0.50:1, the total kernel contaminants for Ikwube, Palm Ash and Sandy Loam is $4.78 \%, 0.41 \%, 4.60 \%$ and $2.68 \%$ respectively. This shows that clay has the highest contaminant while Ikwube has the lowest contaminant at 0.50:1 slurry ratio. Findings from Table 4 shows that for the separation carried out with Clay, Ikwube, Palm Ash and Sandy Loam at 0.30:1 slurry ratio, clay has the largest shell recovery, of $100.00 \%$, followed by Ikwube which produced $99.58 \%$ recovery, and then by Palm Ash recovering 92.90\% and lastly Sandy Loam which recovered the lowest quantity of kernel at $87.98 \%$.

In the same vain at $0.50: 1$, from Table 4 the total kernel contaminants for clay, Ikwube, Palm Ash and sandy loam is $0.00 \%, 6.80 \%, 17.10 \%$ and $25.32 \%$ respectively. This shows that sandy loam has the highest contaminant while clay has the lowest contaminant at 0.50:1 slurry ratio.

Since the objective of this research is to investigate the possibility of using Ikwube, Palm Ash and Sandy loam as a substitute for clay in the heavy media separation (HMS) of oil palm shell from its kernel, the results of clay is taken to be a standard optimum condition that can be used to compare with the result of the study. Generally, the ratio by weight of dry clay to water was $0.30: 1$, the specific gravity, $\mathrm{pH}$, and viscosity of the slurry produced were about 1.16, 9.22, and $3.5 \mathrm{cP}$, respectively. In addition, the kernel recovery rate was $100.00 \%$ with a purity of $99.54 \%$ and the efficiency was $99.68 \%$.

However, the optimum separation conditions using Ikwube were $0.30: 1$ dry media to water ratio by weight which produced a slurry specific gravity of 1.12 , a $\mathrm{pH}$ of 9.98, and viscosity of $5.50 \mathrm{cP}$. This condition produced a kernel yield of $100.00 \%$ with a purity of $100 \%$ and the efficiency was $97.72 \%$.

Moreover, using dry Palm Ash to water at a 0.20:1 weight ratio, it was found that the slurry specific gravity, $\mathrm{pH}$, and viscosity were $1.07,12.29$, and $6.5 \mathrm{cP}$, respectively. More importantly, the kernel recovery rate was $70.01 \%$ while the purity was $98.08 \%$ and the efficiency was $70.08 \%$.
Lastly, using dry Sandy Loam to water at same 0.20:1 weight ratio, it was found that the slurry specific gravity, $\mathrm{pH}$, and viscosity were $1.04,10.12$, and $8.5 \mathrm{cP}$, respectively. The optimum condition for the kernel recovery rate was $73.23 \%$ while the purity was $99.98 \%$ and the efficiency was $72.20 \%$.

In the comparison with the kernel recovery for all types of studied media, it was apparent that the Ikwube media slurry is the most suitable media to remove the oil palm kernels from the shells with kernel recovery 100\%, $98.93 \%$ and $95.00 \%$ in three media slurry ratios of $0.30: 1, \quad 0.40: 1$, and $0.50: 1$ respectively. So when compared with commercial Clay, Ikwube is a very good substitute because it is economically useful for such separation due to its lower cost and because Ikwube media has $\mathrm{pH}$ value for all ratios higher than 9 , and the efficiency of kernels recovery is higher than 95\% in about three slurry ratios.

Consequently, both the Palm Ash and Sandy loam types of media are not efficient substitutes for clay in the separation process producing very low comparable percent recovery and purity of the kernels.

On the other hand, the results from Table 4 indicated that the shell recovery increases with increase in viscosity for every type of media slurries. Moreover, it was found that the maximum shell recovery is $100 \%$, $99.58 \%, 98.90 \%$ and $97.98 \%$ at media slurry ratios $0.5: 1$ for clay, Ikwube, Palm Ash and Sandy loam.

\section{CONCLUSION}

The need for an alternative/substitute to clay soil in preparing slurries for the wet separation of oil palm kernels from its shell cannot be overemphasized as clay soil may not be available in some areas. This work has studied Ikwube as a possible substitute and the results obtained are highly promising. The physical characteristics of the media slurries prepared with the various samples were considered and the results show that the suitable separating conditions were found in which media slurry has specific gravity between 1.06 and $1.12 \mathrm{pH}$ value in the range of $9.23-10.09$ and high viscosity; while the average specific gravity of kernel and shell are respectively 1.04 and 1.28 . At these conditions, kernels recoveries of about $95-100 \%$ were achieved with Ikwube. The result shows that separation efficiency increases with increase in viscosity and the specific gravity for each media slurry ratio, which implies that the new media 'Ikwube' is suitable for the oil palm kernels and shells separation when considering economic cost and separation efficiency.

\section{REFERENCES}


[1] Mensink. R. P. and Katan M. B. "Effect of a diet enriched with monounsaturated or polyunsaturated fatty acids on levels of low-density and high-density lipoprotein cholesterol in healthy women and men". NEngl J Med;321: 436-41, 1992.

[2] Alonso L. "Determination of transfatty acids and fatty acid profiles in margarines marketed in Spain". Journal of American Oil Chemists Society 77, pp 131136, 2000.

[3] Badmus, G. A. Design of Vertical Shaft Centrifugal Palm Nut Cracker Seminar Paper Presented to Nigerian Society of Agriculture, Makurdi, Nig., pp. 2448,1990 .

[4] Nasser, M. S. and James, A.E. Settling and Sediment Bed Behaviour of kaolinite in Aqueous Media. Separation and Purification Technology, 51: 10-17, 2005.

5] Hartley, C. W. S. The Project of Oil Palm and the Extraction in the Oil Palm, London: Longman Publishers, pp: 40-48, 1987.

[6] Oke P. K. "Development and Performance Evaluation of Indigenous Palm Kernel Dual Processing
Machine", Journal of Engineering and Applied Sciences, Medwell Journal, 2007.

[7] Amoah, J. y., Aggey, M., and Annumu, S. "CrackedMixture Sieving Rates and Efficiencies In Small Scale Palm Nut Processing In Ghana". Ghana Journal of Science. 44 (1): 103-105, 2007.

[8] Kwasi and Poku, K. Traditional Techniques and Innovations in Small Scale Palm Oil Processing. Retrieved Oct 03, 2010, From FAO Agricultural Services Bulletin. 2002.

[9] Ferrara, G., and Meloy, T. P. "Low Dense Media Process: a New Process for Low-Density Solid Separation". Journal Powder Technology, 103: 151$155,1999$.

[10] Asiedu, J. J. Processing Tropical Crops and Technological approach. MacMillan Press Ltd London Basingstoke. 1989.

[11] Akubuo, C. O. and Eje, B. E. "Palm Kernel and Shell Separator". Journal of Biosystems Engineering, 81 (2): 193-199, 2002. 